\title{
Usability of Web-based Knowledge Portals to Support Educational Research Organizations: A Case Study
}

\author{
Muthu Kumar and Uma Natarajan \\ Nanyang Technological \\ University, Singapore
}

\author{
haribol.kumar@gmail.com; \\ numa@nie.edu.sg
}

\author{
John G. Hedberg \\ Macquarie University, \\ Sydney, Australia
}

john.hedberg@mq.edu.au

\begin{abstract}
In this article we discuss usability of a Web-based knowledge portal that was developed to support knowledge management activities of an educational research organization. The original portal system initially experienced high levels of user participation. However, this trend has been recently reversed with flagging log-in access rates. Consequently, a criterion-based usability survey instrument was designed and implemented online to gather users' responses and comments. The survey outcomes indicated that a large number of respondents used the portal sporadically, with a significant number being completely unaware of many of its services. Based on this feedback, the existing portal was revamped to ensure more user-centric design that focused on the cornerstone aspects of user control, ease of navigation, personalization services, and classification of project listings.
\end{abstract}

Keywords: Knowledge portal, knowledge management technologies, web-based collaboration, web usability

\section{Introduction}

The Centre for Research in Pedagogy and Practice (CRPP) is housed within the National Institute of Education in Singapore. The Centre brings together researchers, educators and administrators for research and development of new and innovative ways of teaching and learning. The Centre's key research goal is to redesign pedagogy in order to enhance instructional practices which in turn will help students face the challenges of the global economies. With these objectives in mind, the Centre provides evidence as the basis for future educational policy and decision making in Singapore.

Material published as part of this journal, either on-line or in print, is copyrighted by the Informing Science Institute. Permission to make digital or paper copy of part or all of these works for personal or classroom use is granted without fee provided that the copies are not made or distributed for profit or commercial advantage AND that copies 1) bear this notice in full and 2) give the full citation on the first page. It is permissible to abstract these works so long as credit is given. To copy in all other cases or to republish or to post on a server or to redistribute to lists requires specific permission and payment of a fee. Contact Publisher@InformingScience.org to request redistribution permission.
As part of its efforts to provide reports, the centre launched its web-based knowledge portal in August 2003, called the CRPP knowledge portal. This portal was designed to create and share research based information amongst its distributed teams of academics, researchers and school collaborators. It is based upon a business model concept - a website serving as the gateway access point to data and applications. An ele- 
mental goal of the portal development was to create a central repository that could capture, store, and disseminate the empirical findings and intellectual input of its various stakeholders. The conceptual design of the portal was done by an instructional design team, supported in its efforts by the management staff of the Centre. The portal was developed by a third party vendor. The conceptual design of the portal was based upon the heuristics of a functional framework that intended to:

a) Capture and document the knowledge generated from the Centre's more than 60 research projects.

b) Systematically organize and make accessible the different projects' proposals, its cases for support, research designs, findings and pedagogical implications.

c) Share and dispense other relevant information that is collectively for and by the teams.

Building upon this foundational knowledge management structure, the portal also has an open discussion forum where both CRPP's working staff and invited members of the public could participate in contributing ideas of mutual concern that have an impact upon the educational fraternity. Each research project has its own private collaborative work space with controlled access where team members could upload working documents, share content within these documents with fellow team members, solicit constructive feedback in improving content and ultimately have the documents assessed by project investigators or managers to ascertain if the documents can be published in the public domain for public consumption. Within each of these project workspaces, discussions forums were embedded to engender a communicative milieu, one that promotes dialogue on project updates and progress between team members who due to their busy schedules might otherwise not have sufficient time for face-to-face interactions. An additional service provided in the portal was a listing of the profiles, biographies, publications and contact details of CRPP's working staff. Yet another section in the portal disseminates information on upcoming events such as workshops and conferences hosted by CRPP. This information is vital for the general teaching community in keeping abreast of recent research developments in the education field. There is also a section that advertises career opportunities within CRPP and this can be viewed by the general public as well. The large database of information hosted by the portal is searchable using a basic search function that allows users to easily retrieve required information.

While the portal was designed so that key stakeholders could put their reports and public information directly on the publicly accessed website, the concern for data security resulted in the individual decision making facility was turned off and only the IT administrative staff could post to the public site. As a result of the overarching concern for maintaining the accuracy and appropriateness of content posted on the public CRPP portal, the initial design was modified and the portal's locus of control became largely concentrated in the hands of the small administrative IT team. Thus, most of the described features and services were largely managed by the IT team and information was normally updated on a periodic, just-in-time basis. While each staff member of the research centre was individually assigned a username and password to access the system, they could only post content on the site sections where they were project team members and not on the publicly accessible sections. The portal was accessible anytime, anywhere and its users could access the organization's data remotely.

Initially the take-up rate of the portal was encouraging with the frequency of visitations and login access of the various features of the portal, especially by CRPP staff steadily increasing over the months. The portal experienced considerably large amounts of web traffic in the early phases of its rollout. However, eighteen months later, there has been a reversal in this trend with the usage rates sharply declining despite an exponential rise in CRPP's staff strength. 
Although the portal was deemed to have been developed based upon a user-centric design model, when it came to sustained, regular usage there appeared to be some critical dissuading factors. Sensing that something was amiss, the management of the Centre initiated a usability evaluation study to investigate the actual reasons behind the waning usage rates of the portal. The primary goal of the study was to suggest improvements, if necessary to the current portal design, in alignment with user satisfaction feedback to better promote the portal's role as the main knowledge management platform for the Centre.

\section{Literature Review}

Bailey and Pearson (1983) examined the causal relations of user involvement on system usage and information by means of an empirical study. According to them, user involvement in the development of information systems enhances both system usage and users' satisfaction with the system. They measured user satisfaction on Internet portals using a 5 component scale whose elements were content, accuracy, format, ease of use, and timeliness. They recommend that future research could identify additional components of satisfaction that are specific to web-based environments or work-related environments.

According to the International Standards Organization (1998) ISO 9241-11), usability is defined in terms of efficiency, effectiveness and user satisfaction. Bevan (1997) similarly defines usability as "the extent to which a product can be used by specified users to achieve specified goals with effectiveness, efficiency, and satisfaction in a specified context of use". Dillon's (1998) P3 model refers to usability as the extent to which users can exploit the utility of the system. Key amongst these three constructs is user satisfaction since it is an indirect measure of the other two characteristics. User satisfaction is measured by users giving feedback and is instrumental in continuously improving and reworking on the design and content of a system.

There is a growing need for evaluating web usability in general and user satisfaction in particular. User satisfaction as a key function of usability is a vital factor as part of the development lifecycle in determining and measuring usability goals. Web usability specifications describe how it can be applied to specify and measure the usability of products. For this reason, companies and designers have realized that usability studies (also called usability testing or evaluation) are an essential part of the web development and implementation processes. Usability studies enable designers to learn from representative users if the site performs in anticipated ways. Systems with equivalent utility may result in different levels of usability depending on how the design is implemented.

The concept of user satisfaction essentially consists of ensuring that the actual experiences of users on the designed website match the experiences one expects them to have. The success of user experiences stems from being keenly interested in users who are unable to complete critical tasks on your site. Dillon (1998) also notes that users may express a preference for a system based on personal judgment, previous experience, aesthetics, cost etc. Therefore, the final driver of use must be the user's attitude to the technology. The goals of usability testing ought to be directed towards toward reducing their numbers and investigating how people use a specific website or web-based application. Tests can be conducted one-on-one, in small groups or with large numbers of general users. The tests may take place in a formal lab or in a more typical environment like home or work. Usability testing overall tends to be very task oriented in testing for usefulness, satisfaction and ease of use (Ellis \& Ellis, 2002).

One of the most productive ways to gauging user satisfaction of electronic information systems is through surveys and questionnaires. Slaughter, Harper and Norman (1994) showed that online surveys produced valid enough results and these surveys encouraged participants to return valuable comments. Their Questionnaire for User Interaction Satisfaction (QUIS) focused on user's 
perceptions of interface usability as is expressed in specific aspects of the interface functionalities. It was administered using standard HTML forms that let users select items from pull-down lists, click on check boxes and radio buttons, and enter text and comments into text areas. Such a presentation and layout style is similar to the paper version of the questionnaire, in displaying multiple questions per page and comment areas at the end of each section. Testing was done on the World Wide Web (WWW), with data being collected for reliability and validation assessments. In addition to being effective and returning valuable user data, studies have shown that online surveys are cost-effective as well since the participating users choose to electronically access the surveys at any time and from the convenience of any location.

\section{Methodology}

A critical attribute of the effectiveness of technology adoption and web systems usability is users' perceived levels of satisfaction with the systems with which they are interacting (Zazelenchuk \& Boling, 2003). A review of some of the available portal usability survey instruments such as the Questionnaire for User Interaction Satisfaction, (QUIS, retrieved online http://lap.umd.edu/QUIS) though informative and insightful, did not comprehensively address all the specific needs and issues involved in wanting to conduct a usability study on CRPP's knowledge portal. None of the surveys completely matched the range of web usability requirements and specifications involved in testing CRPP portal's robustness and efficacy. Thus these surveys could not be used in their entirety and consequently there was a need to develop a more context-specific web usability questionnaire that would pertinently address issues related to evaluating CRPP's portal. Items in the reviewed survey instruments which were found to be relevant were extracted to construct the usability survey for this study (see Appendix). While some of the items were used directly, several were adapted and modified.

CRPP staff normally functions on tight schedules - having to juggle a number of research-related work activities to ensure that project deadlines are met. With this constraint in mind, the survey was deliberately kept short and succinct to encourage widespread participation amongst staff. A total of ten quality items were thus framed. Though Likert scales are commonly used in administering questionnaires (Burns, 2000), in the case of this study they were not used since they do not yield the expected precision in empirical findings to determine patterns and preferences of usage of the various constituent components of CRPP's portal. To better measure the construct of web usability, in particular, user satisfaction, the responses to some of the items in our survey were choices that were frequency counts of actual usage. A few other items sought to elicit users' perceived ratings of levels of importance to intended enhancements in a revamped portal design. Interspersed within the survey were open-ended response questions to gather participants' opinions on the individual functions available as well as desired functions within the portal.

The survey was administered online for a period of three weeks to encourage all staff to access the survey at convenient times to post their responses and comments to the various criterionbased items framed in the survey. An online survey was deemed to be the most effective way of reaching out to and capturing feedback from as large a possible number of scattered staff members who work at various locations and on different projects and schedules. Out of total registered staff strength of 90,55 users responded to the survey. This translates to an acceptable return rate of $62 \%$.

\section{Findings}

The majority of the users who participated in the survey were researchers in the organization $(58 \%)$ and about $27 \%$ were academic staff. $29 \%$ of these respondents said that they accessed the portal 1-2 times a month, $36.5 \%$ accessed it several times a month and $5 \%$ accessed the site on a daily basis. (Refer to Tables 1 and 2.) 
Table 1: Association with CRPP

\begin{tabular}{|l|r|r|}
\hline \multicolumn{1}{|c|}{ User Group } & Frequency & Percent \\
\hline $\begin{array}{l}\text { Full time academic } \\
\text { staff }\end{array}$ & 2 & 3.6 \\
\hline $\begin{array}{l}\text { Seconded } \\
\text { academic staff }\end{array}$ & 13 & 23.6 \\
\hline Project manager & 3 & 5.5 \\
\hline $\begin{array}{l}\text { Research } \\
\text { assistant/associate }\end{array}$ & 4 & 7.3 \\
\hline $\begin{array}{l}\text { Administrative } \\
\text { staff }\end{array}$ & 1 & 1.8 \\
\hline $\begin{array}{l}\text { Others (please } \\
\text { elaborate) }\end{array}$ & 55 & 100.0 \\
\hline Total & & \\
\hline
\end{tabular}

Table 2: Frequency of using CRPP portal

\begin{tabular}{|l|r|r|}
\hline User Group & Frequency & Percent \\
\hline Everyday & 3 & 5.5 \\
\hline $\begin{array}{l}\text { Several times a } \\
\text { week }\end{array}$ & 8 & 14.5 \\
\hline Once a month & 4 & 7.3 \\
\hline $\begin{array}{l}\text { Several times a } \\
\text { month }\end{array}$ & 12 & 21.8 \\
\hline $\begin{array}{l}\text { Once or twice a } \\
\text { month }\end{array}$ & 16 & 29.1 \\
\hline $\begin{array}{l}\text { Once or twice a } \\
\text { semester }\end{array}$ & 9 & 16.8 \\
\hline Rarely & 2 & 3.6 \\
\hline Never & 55 & 100.0 \\
\hline Total & & 16 \\
\hline
\end{tabular}

When the portal design was originally framed, it was envisaged that staff would log into the portal on a daily basis to conduct their project related knowledge activities and become informed of updates on happenings taking place in CRPP.

When queried on the kinds of information they tend to look out for in visiting the CRPP portal, users responded that they chiefly want to find out more on current projects information and updates on progress, staff biographies and contact details, research projects reports, public presentation slides and related publications. Some of the other auxiliary items mentioned included instructional manuals, workshop materials, resources and administrative forms (refer to List 1 for a selection of common responses).

\section{List 1: Information typically sought after at CRPP portal}

Question: What kinds of information do you typically look for online at CRPP portal?

- Staff and current projects info

- Biographies and contact details

- Research reports and presentations, occasionally publications

- Manuals, workshop materials and resources such as PowerPoint slides of presentations

- Forms and room booking

- Info on administration procedures

- Schedules of talks on CRPP projects and CRPP events updates

Based upon their experiences in actually interacting with the portal, users did give positive albeit limited feedback on the portal's current state of utility to them. This includes features such as access to viewing research projects information and getting to know more about people and courses offered by project staff at CRPP. Other useful facilities mentioned by users are storing and shar- 
ing research information, accessing work-related resources, reading more on CRPP publications and gathering information on international or local conferences (refer to List 2 for a selection of common responses).

\section{List 2: Popular reasons for using CRPP portal}

Question: What is most useful to you on the current CRPP web portal?

- Accessing staff bio-data and project information

- Getting to know more about people, courses and updates on projects of CRPP

- Storing and sharing information

- Accessing work-related resources

- Getting staff contact details such as telephone numbers

- Reading more on CRPP publications

- Getting forms

- Information on conferences

- Comprehensiveness, ease-of-use

Despite listing these services and functions as being beneficial, intriguingly the majority of respondents accessed them infrequently. On average, only 7-13\% of polled users used key features such as project discussion forums, resources, publications and search functions on a daily basis. Even for a more achievable access target rate of weekly logging-in, the results were not better. Notably, a high percentage of about $20-55 \%$ of users was not even aware of these vital services (refer to Table 3).

Some of the reasons for the disappointing levels of usage of the portal were slow speed, and uncertainty and difficulty of access when it comes to uploading and downloading information from the Web site (see List 3 for a selection of common responses). The staff also pointed to the inactive state of the forums. In addition, users were frustrated with the numerous links they needed to access to locate deeply buried documents. This dissuaded them from wanting to use the portal as the default knowledge management tool to storing and sharing project-related information. Rather they preferred using thumb-drives and removable hard-discs as the easier alternatives to information storage. 
Table 3: Frequency of accessing the following services and features on the portal (in \%)

\begin{tabular}{|l|r|r|r|r|r|r|r|}
\hline Feature / Frequency & Daily & Weekly & Monthly & $\begin{array}{r}\text { Not at } \\
\text { all }\end{array}$ & $\begin{array}{r}\text { Not aware } \\
\text { of Service } \\
\text { or Feature }\end{array}$ & $\begin{array}{r}\text { Once or } \\
\text { Twice a } \\
\text { year }\end{array}$ & Total \\
\hline Completed Projects & 1 & 7 & 28 & 6 & & 13 & 55 \\
\hline Current Projects & 9.1 & 10.9 & 29.1 & 14.5 & & 36.4 & 100 \\
\hline Publications & 10.9 & 10.9 & 29.1 & 23.6 & 9.1 & 16.4 & 100 \\
\hline Journals & 9.1 & 9.1 & 29.1 & 21.8 & 16.4 & 14.5 & 100 \\
\hline Resources & 7.3 & 12.7 & 36.4 & 20 & 16.4 & 7.3 & 100 \\
\hline Conferences & 12.7 & 5.5 & 30.9 & 14.5 & 10.9 & 25.5 & 100 \\
\hline Courses & 9.1 & 5.5 & 20 & 29.1 & 21.8 & 14.5 & 100 \\
\hline Public forums & 10.9 & 3.6 & 9.1 & 45.5 & 20 & 10.9 & 100 \\
\hline Project forums & 9.1 & 1.8 & 12.7 & 43.6 & 27.3 & 5.5 & 100 \\
\hline Staff listings & 5.5 & 23.6 & 29.1 & 7.3 & 3.6 & 30.9 & 100 \\
\hline Visitors' listings & 7.3 & 5.5 & 14.5 & 40 & 27.3 & 5.5 & 100 \\
\hline Public Calendar & 9.1 & 3.6 & 16.4 & 50.9 & 10.9 & 9.1 & 100 \\
\hline Project Calendar & 9.1 & 7.3 & 14.5 & 41.8 & 21.8 & 5.5 & 100 \\
\hline Basic Search Function & 12.7 & 7.3 & 23.6 & 40 & 5.5 & 10.9 & 100 \\
\hline $\begin{array}{l}\text { Advanced Search } \\
\text { Function }\end{array}$ & 10.9 & 1.8 & 14.5 & 54.5 & 10.9 & 7.3 & 100 \\
\hline $\begin{array}{l}\text { Logging in to } \\
\text { access/share/upload } \\
\text { additional resources in } \\
\text { project folders }\end{array}$ & 7.3 & 3.6 & 34.5 & 36.4 & 10.9 & 7.3 & 100 \\
\hline $\begin{array}{l}\text { Logging in to } \\
\text { access/share/upload } \\
\text { forms }\end{array}$ & 16.4 & 1.8 & 21.8 & 32.7 & 9.1 & 18.2 & 100 \\
\hline & & & & & & & \\
\hline
\end{tabular}

\section{List 3: Popular reasons for not using the CRPP portal}

Question: What do you least like about the current CRPP web portal?

- Slow speed of network in uploading and downloading info

- The clunkiness, uncertainty and difficulty involved in uploading, publishing materials

- Inactivity in forums and lack of visibility of forums

- The need to click on many layers and inks to find documents

- Font size is too small

- Project folders have documents with backdated info and with empty links 
- Interface - need a site-map

- Too localized - need links to external sites

When asked to indicate a wish list of things that they would like to see in future in the remodelled knowledge portal, an overwhelming majority mentioned a more user-centric design that included incorporating more user-friendly feedback and response-gathering mechanisms, empowering users with greater degrees of autonomy and injecting more flexibility in allowing principal investigators and project managers to independently maintain their project workspace sites and documents housed within them (refer to List 4 for a selection of common responses). Some of the users also desired better search functions to streamline the process of finding documents and links to other international sites and library catalogues. A few users mentioned that the CRPP website needs a site map for ease-of-navigation and effective location of links and web pages. Repeatedly, a number of users advocated more accessible, better advertised discussion forums that rouse users' motivation to want to participate as well as prompt news updates to be posted on ongoing research projects' progress, staff biographies and reports on completed research projects.

\section{List 4: Popular wishes and requests on improving CRPP portal and its features}

Question: What kinds of information or services would you like to see on the new CRPP web portal that is not currently there?

- Putting up samples of completed projects including CRPP standard forms, cases for support, budget proposals, breakdown of funds etc

- More autonomy and accountability for PIs and RAs to maintain their project sites and documents hosted within them

- Instead of flooding e-mail boxes, put up info on courses and workshops on CRPP portal

- Conference info, published research papers and seminar slides and PowerPoint

- Better search functions to find documents according to different categories

- Links to other sites such as library catalogues

- Forums for public for discussions

- Up-to-date forms, detailed administration procedures and minutes of meetings

- Info on feedback, and responses to CRPP projects

Question: Please share any other ideas you have about improving the usefulness of CRPP web portal

- More accessible and better advertised discussion forums

- Wikipedia style layout

- Information on how to do research, researchers' experience, practical do's and don't's of conducting research

- Website needs a more user-friendly, less technical, interactive look

- Updated info on projects progress, staff biographies and minutes of meetings

A significant number (about 70\%) of users rated personalization services as "important or very important" in the revamped portal (Table 4). Over $75 \%$ of users rated the same way the organization of projects according to subject disciplines and research specializations as significantly. This would ease the searching for and locating specific research projects to access relevant informa- 
tion. About $65 \%$ of respondents requested provision of online materials such as standard procedures and instructional manuals on using software and hardware. This is significant in a research organization where the needs of users of technology may differ markedly and might require differentiated technical guidance and support.

Table 4: Importance of services and features

\begin{tabular}{|l|r|r|r|r|r|}
\hline \multicolumn{1}{|c|}{ Feature } & $\begin{array}{c}\text { Not } \\
\text { important }\end{array}$ & $\begin{array}{c}\text { Low } \\
\text { priority }\end{array}$ & Important & $\begin{array}{c}\text { Very } \\
\text { Important }\end{array}$ & Total \\
\hline $\begin{array}{l}\text { Personalisation services in re- } \\
\text { ceiving monthly updates on } \\
\text { CRPP events, projects and } \\
\text { conference updates }\end{array}$ & 12.7 & 16.4 & 52.7 & 18.2 & 100 \\
\hline $\begin{array}{l}\text { Project calendar to inform } \\
\text { members of project specific } \\
\text { events and meetings }\end{array}$ & 20 & 9.1 & 49.1 & 21.8 & 100 \\
\hline $\begin{array}{l}\text { Online materials such as IT } \\
\text { services and procedures and } \\
\text { instructional manuals on soft- } \\
\text { ware and hardware usage }\end{array}$ & 12.7 & 21.8 & 47.3 & 18.2 & 100 \\
\hline $\begin{array}{l}\text { Classification of CRPP pro- } \\
\text { jects according to subject dis- } \\
\text { ciplines and research speciali- } \\
\text { zations }\end{array}$ & 10.9 & 7.3 & 54.5 & 21.8 & 100 \\
\hline
\end{tabular}

\section{Discussion}

As pointed out by Bevan (1997), user satisfaction is an important dimension of measure in evaluating usability and could be viewed as an indirect measure of the quality of system efficiency and effectiveness. The poor access rates as highlighted by the survey outcomes rates evidently indicate low levels of satisfaction amongst users and inferentially, a perceived lack of efficiency and effectiveness of the portal. Obviously, there is a misalignment between the actual experiences of users in navigating through the electronic knowledge space of the portal and the expectations of the ways in which the portal ought to work. The findings from the analysis of users' responses to the administered survey shed more light in understanding deeper users' concerns and underpinning reasoning to explain the low rates of user participation.

The findings revolve around three key issues that impact usability of the CRPP portal and facilitate higher participation rates: user control and ease of navigation, personalization features, and classification of project listings. These three issues are conceptually linked to the goals of usability testing involving usefulness, satisfaction and ease of use as elucidated by Ellis and Ellis (2002). The revamped design of the CRPP portal, whose welcome page appears in Figure 1, has focally addressed these issues. Each will be discussed in turn.

One compelling issue raised by the findings was the large number of staff who did not access the various component features of the portal at all or were not even aware of these features. Public forums and project forums especially had low participation rates and this finding was disconcerting in light of the fact that the original portal design had extensively built-in forums within all project workspaces to foster a more sustained interactive online environment. These forums were envisioned to encourage team members to contribute innovative ideas on research progress direc- 


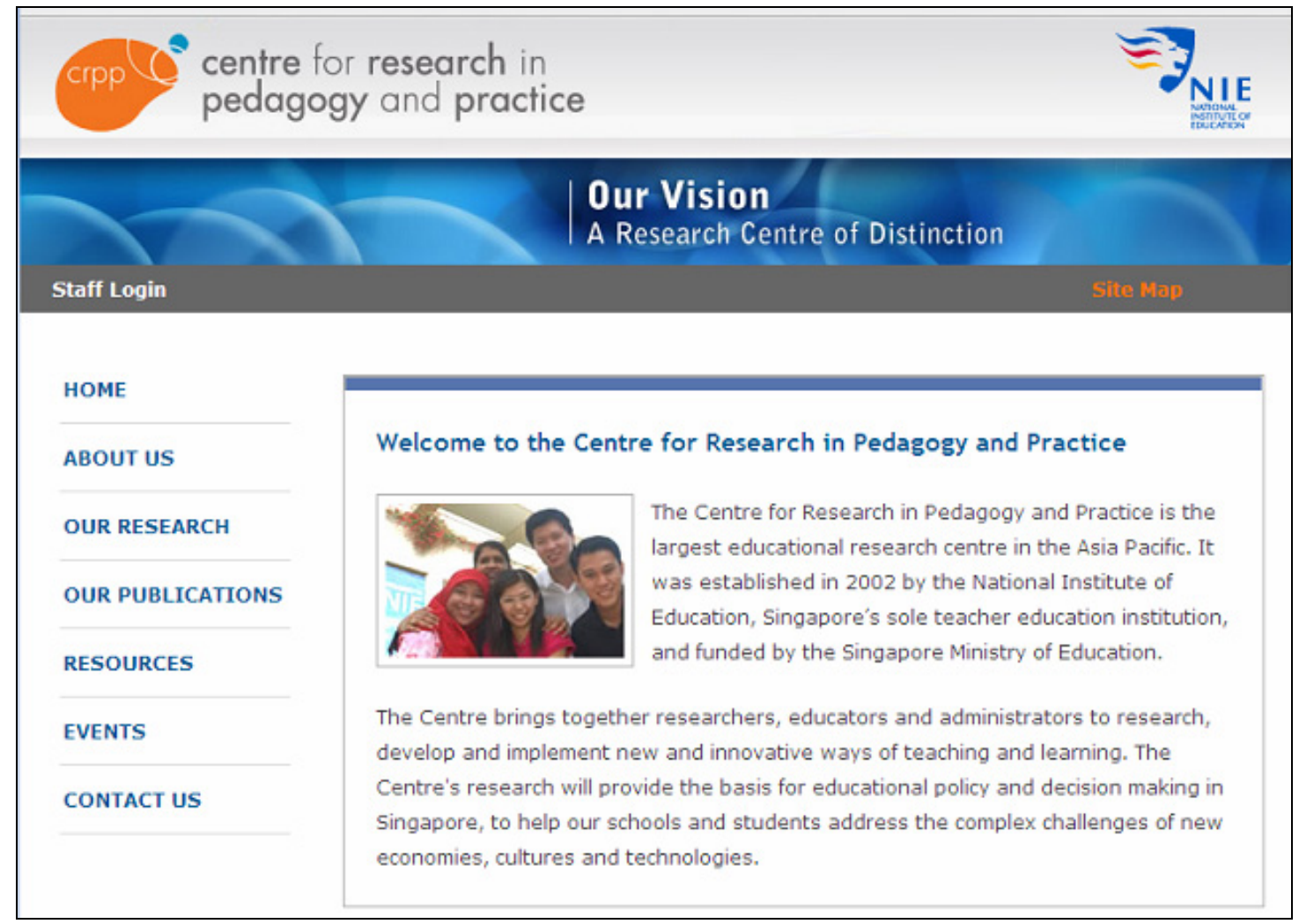

Figure 1. Welcome page of modified CRPP knowledge portal (http://www.crpp.nie.edu.sg)

tions and future development of projects. Furthermore, such forums help to circumvent the difficulties faced by project members who are physically located at a number of different geographic locations. Many of the research projects had stakeholders, who were situated at different sites, such as schools, the ministry of education and university campuses. The forums were targeted to serve as the focal platforms for encouraging interactions and social bonding in advancing the goals of the research projects.

Another intended strength of the current portal system was its structural design that allowed research staff to upload, share, access and publish documents within their respective project workspaces. This was meant to facilitate consolidation and augmentation of individual project's intellectual knowledge capital. Again this facility was largely under-utilized. One staff member commented on the "clunkiness" of the system and the lack of flexibility it afforded in uploading and publishing documents, especially in the public domain of the portal. This resulted in the development of negative attitudes towards use of technology in knowledge management and needs to be responsively addressed. The outcomes of usability testing ought to be aimed at reducing the numbers of disaffected users who have become averse to using technology to complete critical knowledge tasks.

One underlying reason attributed to the sharply declining usage rates for CRPP's portal was the dilemma over the degree of control that could be devolved to users to autonomously manage and use the portal's functions. The tension arises out of the Centre management's prime concern over maintaining the integrity and confidentiality of the documents being circulated within the portal system. Due to the highly sensitive nature of the documents being circulated, there was a need to ensure that there is no unauthorized access to these documents. Thus, many layers of control were 
factored in the original portal design which inevitably constrained user autonomy and made navigation within the portal structure more difficult. Inextricably, portal productivity and ease of usage was compromised, contributing to flagging interest levels in utilizing the portal as the platform to enacting projects' knowledge management activities.

The revamped portal design strives to strike a more healthy balance between the need for tight controls in ensuring content security and the calls for greater flexibility in self-managing the portal's features. Accordingly, discussion forums in the project workspaces which are hosted within the private domain of the portal will be moderated and managed independently by project investigators with team members having a free reign in posting comments, responding to discussion threads and uploading articles and documents for discussions. However, the main discussion forum in the public domain would continue to be regulated and monitored by the IT administrative team to ensure that postings conform to normative codes of ethical, professional conduct and do not undermine the high quality of work being carried out by the research organization. Similarly, controls in uploading, editing and sharing documents within project workspaces would be relaxed in the new portal design, with all members having equal rights to performing these activities.

However, rights to publishing documents in the public domain would again be kept in the hands of the administration IT/management team to maintain the integrity of information being made accessible to the general public.

Personalization features probably account for most of a portal's ability to attract and retain users (Zazelenchuk \& Boling, 2003). Personalization is an important function of system usability in improving efficiency, effectiveness and satisfaction. This design principle was easily corroborated by the data finding where the predominant majority of polled staff $(70 \%)$ strongly favoured personalization services. This was achieved with a reasonable measure of success since the new portal was configured to periodically but automatically send out portal updates to users' email accounts on information such as CRPP events, projects and conferences. This would encourage users to revisit the knowledge portal and log-in on a more frequent basis to access the details of these updates, thus improving usability rates. To allay the concerns of some who felt that this might clog-up limited email spaces, only brief statements of updates on key events and conferences would be emailed out. Moreover, the modified design of the portal was orientated towards a Wikipedia style format which empowers staff to promptly update their own biography (inclusive of publication listings) and project description web pages without the need for final approval from the administration IT team. This ensured that these project web pages would have updated information for public user consumption and thus they would feel motivated to want to visit the website regularly to access current information. Engaging users in the development of the portal content would conversely have a positive effect in enhancing system usage and involvement (Bailey \& Pearson, 1983).

The original portal design had all the projects lumped together and listed in alphabetical order. As the number of approved research project grew bigger, the listings became more unwieldy in terms of ensuring good organization and visual clarity of project-related information. This was another functional feature of the electronic knowledge portal environment that contributed to depressed user motivation and satisfaction levels. This shortcoming was identified through the user survey and rectified with a more improved layout format where projects were listed according to two broad layers of categorization. The first layer consist of three main categories: on-going core research projects, specific focus projects and completed research projects. The core research projects were further thematically sub-divided according to the different component panels that focused on various research strands.

The specific focus projects were also similarly segregated but according to their specializations of subject disciplines such as language and literacy, mathematics, science and Information and Communication Technologies (ICT). It was hoped that such a presentation layout of information 
display would allow users to more easily search for relevant projects and ensure less cognitive load for users in accessing and processing information. By identifying trends on user needs and the specific contexts of knowledge access within the online environments, enhanced user satisfaction could be achieved.

\section{Conclusion}

CRPP's web portal was designed and developed to share and manage a central knowledge database where information could be consolidated and distributed to all its members and the general public-at-large. It allowed users to easily access and retrieve relevant information online. In recent times, the portal has failed to fully realize the desired knowledge management goals. It has suffered declining rates of usage. In order to effectively encourage the adoption of the portal's use among its members and to make it more relevant to their needs, a usability survey was conducted to improve upon its design. This was a positive step aimed towards making the portal more successful in terms of usage and application. Knowledge portals can become confusing and complicated and people may become averse to using them if users find them difficult to navigate or find their content uninformative. This in turn can curtail the portal's growth and risk the eventual adoption of the same. The case also shows how a survey instrument can be used for studying portal usability in order to develop a more informed understanding of needs of the CRPP portal's users. Our case contributes to the practice of designing and managing knowledge portals in research organizations. From the academic perspective, this study contributes to the current limited scholarship on technology-mediated knowledge sharing and management environments in educational research organizations.

\section{References}

Bailey, J.E. \& Pearson, S.W. (1983). Development of a tool for measuring and analyzing computer user satisfaction. Management Science, 29(5), 530-545.

Bevan, N. (1997). Position paper for Conference on Human Factors in Computing Systems, March 22-27, 1997. Retrieved October 20, 2000 from http://www.acm.org/sigchi/webhci/chi97testing/bevan.htm

Burns, R. B. (2000). Introduction to research methods. NSW: Pearson Education.

Dillon, A. (1998). Cultural analysis and what designers need to know - A Case of sometimes too much, sometimes too little and always too late. ACM Journal of Computer Documentation, 22(1), 13-17.

Ellis, P. \& Ellis, S. (2002). Measuring user experience. Retrieved Aug 30, 2006 from http://www.webtechniques.com/archives/2001/02/ellis/

International Standards Organization. (1998). ISO 9241: Ergonomic requirements for office work with visual display terminals.

Slaughter, L., Harper, B., \& Norman, K. (1994). Assessing the equivalence of the paper and online formats of the quis 5.5. In Proceedings of the $2^{\text {nd }}$ Annual Mid-Atlantic Human Factors Conference. Retrieved June 10, 2005 from http://lap.umd.edu/lapfolder/papers/shn.html

Zazelenchuk, T. W \& Boling, E. (2003). Considering user satisfaction in designing web-based portals. Educause Quarterly, 1, 35-40. 


\section{Appendix}

CRPP Portal Survey

Dear CRPP staff,

We are conducting a survey to gauge users' needs and requirements as we are in the process of revamping the current CRPP portal to improve on its design interface and functionalities. Kindly participate in this short survey and giving us your valuable feedback. Thanks for your inputs.

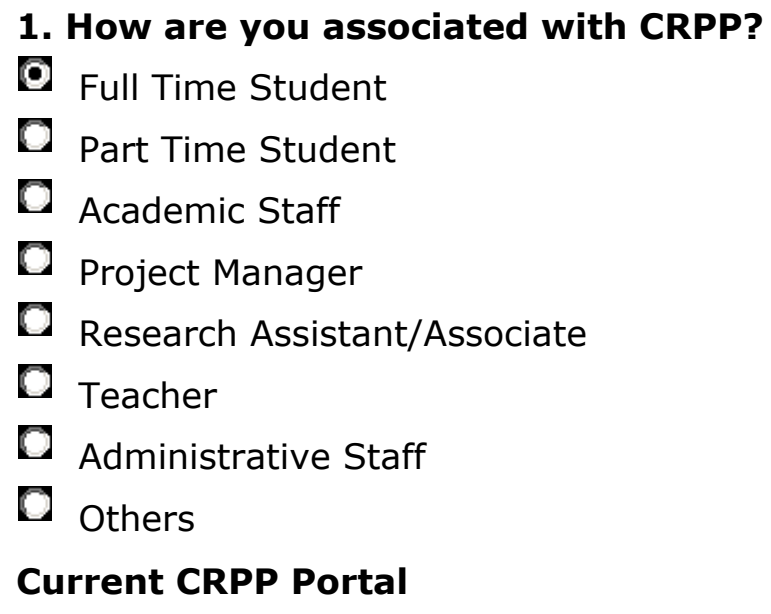

\section{Current CRPP Portal}

2. How often do you use the CRPP portal http://www.crpp.nie.edu.sg ?

Q Every Day

D Several Times a Week

Once a Month

D Several Times a Month

O Once or Twice A Semester

O Other

3. What kinds of information do you typically look for online at CRPP portal?

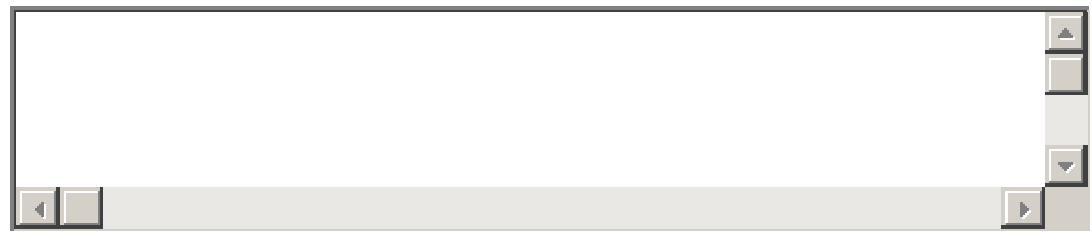

4. What do you find MOST useful about the current CRPP web site?

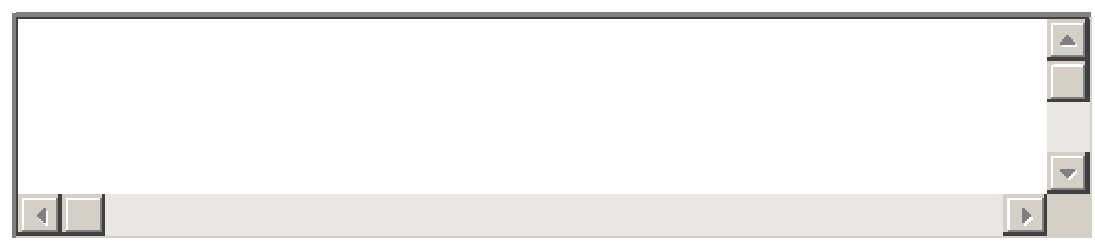


5. What do you LEAST like about the current CRPP web site?

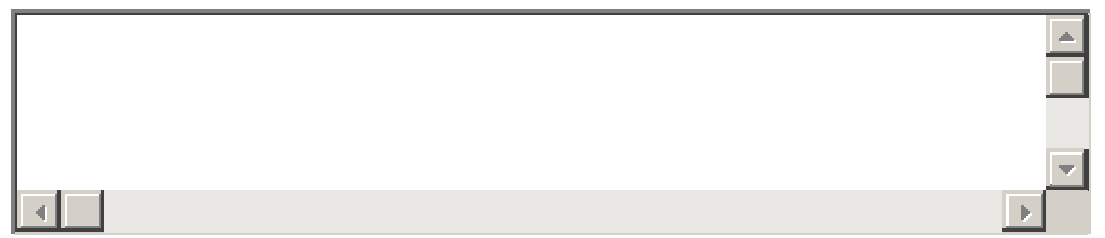

6. How often do you access the following services and features in the portal? (Daily, Weekly, Monthly, Not at All, N/A)

Completed projects

Current projects

Publications

Journal

Resources

Ethics

Conferences

Courses

Public Forums

Project Forums

Staff Listings

Career

Visitors Listings

Public Calendar

Project Calendar

Basic Search Function

Advanced Search Function

Logging in to access/share/upload additional resources in project folders?

Forms

\section{Revamped CRPP Portal}

7. What kinds of information or services would you like to see on the new CRPP web portal that is not currently there?

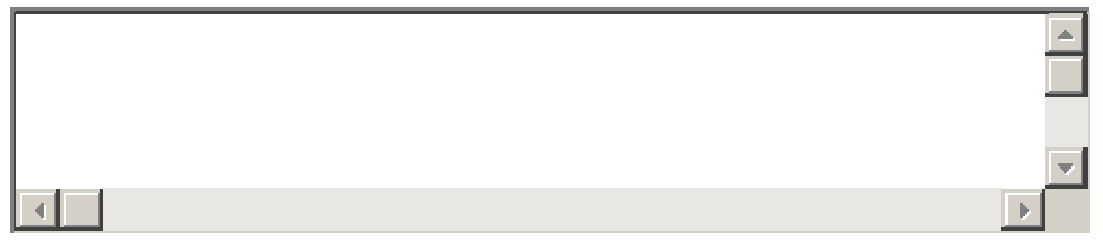




\section{Please share any other ideas you have about improving the usefulness of CRPP we portal:}

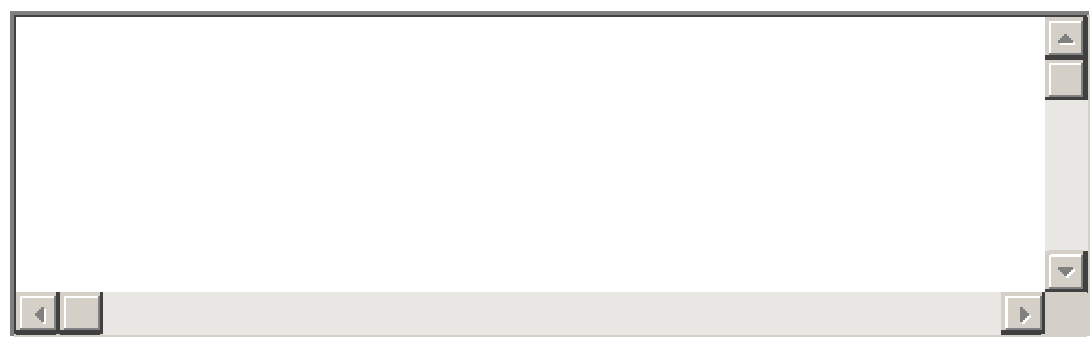

\section{How would you rate the level of importance if the following services and features are made available in the revamped portal? (Not important, low priority, important, very important, N/A)}

Personalisation services in receiving monthly updates to your email account on CRPP events, projects and conference updates

Project calendar to inform members of project specific events and meetings

Online materials such as IT services and procedures and instructional manuals on software and hardware usage

Classification or CRPP projects according to subject disciplines and research specializations

\section{Include your email address if you would like to hear more about the pro- gress of the CRPP portal project.}

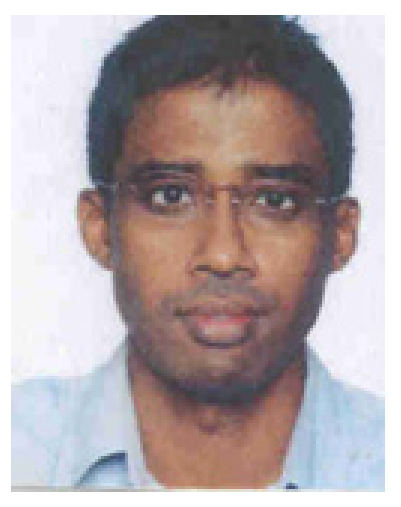

\section{Biographies}

S. L. Muthukumar obtained his Bachelors in Engineering (Civil) and completed his Postgraduate Diploma in Education at the National Institute of Education specializing in the subjects of Mathematics and Physics. He has extensive teaching experience in schools in Singapore and has also worked as an educational technologist. Currently he is an instructional designer with the Centre for Research in Pedagogy and Practice at the National Institute of Education, Nanyang Technological University, Singapore. His areas of research interest include e-learning design frameworks and factors that impact these frameworks, multimedia design and its cognitive implications as well as knowledge management technology. 


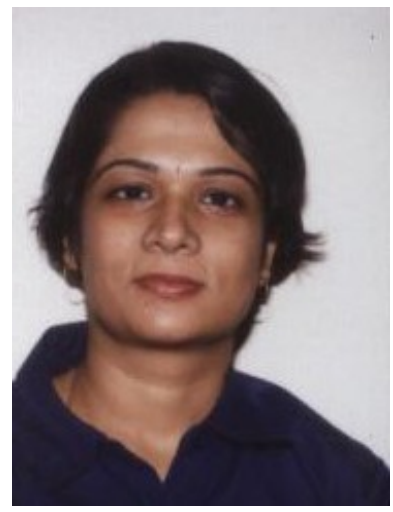

Uma Natarajan is a Research Associate at the Centre for Research in Pedagogy \& Practice at National Institute of Education, Nanyang Technological University, Singapore. Her research interests include atrisk youth and technology curriculum. Her experiences include a career in India as a research chemist with a pharmaceutical company after obtaining a Masters in Chemistry followed by a study of psychology and sociology in the field of education and having taught physical sciences at the secondary school level. Since 2000, she began consulting a number of schools in Singapore to integrate ICT (Information \& Communication Technology) in education and helped them build digital repositories. She is currently pursuing a Ph.D. in the field of at-risk youth and technology.

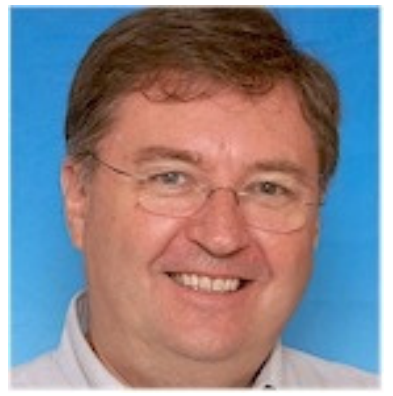

Dr John G Hedberg is Millennium Innovations Chair in ICT and Education and Director of the Macquarie ICT Innovations Centre at Macquarie University, which develops innovative programs in technologyenhanced learning for students and teachers. He has wide experience in the design of open and distance learning programs, and is known for the constructivist learning environments he has designed. These include StageStruck, an interactive theatre CD-ROM for which he received a British Academy award. He has been Professor of Learning Sciences and Technologies at Nanyang Technological University, where he directed several research projects exploring the role of technologies in engaging students in mathematics, science, history and geography classrooms.

Dr Hedberg is the author of work on navigation, cognition and multimodality, and design and evaluation in interactive multimedia. His most recent book is Evaluating Interactive Learning Systems, with Thomas Reeves. He is also the Editor-in-Chief of Educational Media International. 